\title{
Calcineurin Plays Different Roles in Group II Metabotropic Glutamate Receptor- and NMDA Receptor-Dependent Long-Term Depression
}

\author{
Sheng-Tian Li, ${ }^{1,3}$ Kunio Kato, ${ }^{2}$ Kazuhito Tomizawa, ${ }^{3}$ Masayuki Matsushita, ${ }^{3}$ Akiyoshi Moriwaki, ${ }^{3}$ \\ Hideki Matsui, ${ }^{3}$ and Katsuhiko Mikoshiba1 ${ }^{1,4,5,6}$ \\ ${ }^{1}$ Mikoshiba Calciosignal Net Project, Exploratory Research for Advanced Technology, Japan Science and Technology \\ Corporation, Tokyo 113-0021, Japan, 2Department of Neuropsychiatry, Kochi Medical School, Kochi 783-8505, Japan, \\ ${ }^{3}$ Department of Physiology, Graduate School of Medicine and Dentistry, Okayama University, Okayama 700-8558, Japan, \\ ${ }^{4}$ Division of Molecular Neurobiology, Department of Basic Medical Science, Institute of Medical Science, University of Tokyo, \\ Tokyo 108-8639, Japan, ${ }^{5}$ Calcium Oscillation Project, Japan Science and Technology Corporation, Tokyo 108-8639, Japan, \\ and 'Laboratory for Developmental Neurobiology, RIKEN Brain Science Institute, Wako, Saitama 351-0198, Japan
}

We investigated metabotropic glutamate receptor (mGluR)dependent long-term depression (LTD) in hippocampal CA1 pyramidal neurons of 6- to 8-d-old [postnatal days 6-8 (P6-P8)] and 21- to 25-d-old (P21-P25) rats. In P6-P8 rats, induction of LTD depended on the activity of group II mGluRs. In P21-P25 rats, however, this LTD disappeared, and instead, NMDA receptor (NMDAR)-dependent LTD appeared. A bath containing a specific calcineurin (CaN) inhibitor restored the group II mGluRdependent LTD in the neurons of the P21-P25 rats. Although postsynaptic injection of $\mathrm{CaN}$ inhibitors suppressed NMDAR- dependent LTD, it did not affect induction of group II mGluRdependent LTD. These results demonstrate that CaN plays different roles in the induction of two forms of LTD: presynaptic CaN inhibits group II mGluR-dependent LTD, whereas postsynaptic $\mathrm{CaN}$ facilitates NMDAR-dependent LTD. These findings are the first demonstration in vitro of group II mGluR-dependent LTD that is negatively regulated by $\mathrm{CaN}$ via an age-dependent mechanism.

Key words: synaptic plasticity; long-term potentiation; LTD; mGluR; NMDA receptor; hippocampus
Synaptic plasticity, such as long-term potentiation and long-term depression (LTD), is believed to form the cellular basis of learning and memory in mammalian brains (Bliss and Collingridge, 1993; Lisman, 1994). Two mechanistically distinct forms of LTD coexist in synapses in the CA1 region of the hippocampus (Oliet et al., 1997; Nicoll et al., 1998). Induction of one form depends on activation of NMDA receptors (NMDARs) (Malenka and Nicoll, 1993; Bear and Malenka, 1994; Thiels et al., 1996), and induction of the other depends on activation of metabotropic glutamate receptors (mGluRs) (Stanton et al., 1991; Bolshakov and Siegelbaum, 1994; Yang et al., 1994; Oliet et al., 1997; Overstreet et al., 1997; Nicoll et al., 1998). It is now well established that protein dephosphorylation by protein phosphatase $2 \mathrm{~B}$ [also called calcineurin $(\mathrm{CaN})]$, the only protein phosphatase that is activated by $\mathrm{Ca}^{2+} /$ calmodulin in the CNS, has a critical role in the induction of NMDAR-dependent LTD (Mulkey et al., 1994; Hodgkiss and Kelly, 1995).

In contrast, little is known about the mechanisms of mGluRdependent LTD. Several studies indicate that mGluR-dependent LTD was induced in neonatal rat hippocampal CA1 neurons (of rats 3-12 d old) but not in rats older than $28 \mathrm{~d}$ (Bolshakov and Siegelbaum, 1994; Overstreet et al., 1997), suggesting that an age-dependent mechanism may be involved in the induction of

\footnotetext{
Received Nov. 5, 2001; revised March 26, 2002; accepted April 9, 2002.

We thank K. Kohda for discussion and comments on this manuscript. We thank A. Hoshino for technical assistance in slice preparation.

Correspondence should be addressed to Dr. Hideki Matsui, Department of Physiology, Graduate School of Medicine and Dentistry, Okayama University, 2-5-1 Shikata, Okayama 700-8558, Japan. E-mail: matsuihi@cc.okayama-u.ac.jp. Copyright (C) 2002 Society for Neuroscience $0270-6474 / 02 / 225034-08 \$ 15.00 / 0$
}

mGluR-dependent LTD. On the other hand, although three groups (I, II, and III) of mGluRs have been reported, each exhibiting different subcellular localization and functions (Pin and Duvoisin, 1995; Petralia et al., 1996; Wright and Schoepp, 1996; Anwyl, 1999), little is known about which group is involved in mGluR-dependent LTD in neonatal rat CA1 neurons. We investigated the mGluR-dependent LTD by using a specific group I and/or group II mGluR agonist or antagonist in 6- to 8-d-old [postnatal days 6-8 (P6-P8)] and 21- to 25-d-old (P21-P25) rats. Our results show that $\mathrm{CaN}$ negatively regulates group II mGluRdependent LTD in an age-dependent manner and that presynaptic and postsynaptic CaN plays different roles in induction of NMDAR- and group II mGluR-dependent LTD.

\section{MATERIALS AND METHODS}

Hippocampal slices were prepared from P6-P8 and P21-P25 Sprague Dawley rats as described previously (Kato et al., 1991). Rats were anesthetized with diethyl ether and decapitated, and the hippocampi were then rapidly dissected. Transverse slices $(500-\mu \mathrm{m}$-thick) of the hippocampus were cut at $0-4^{\circ} \mathrm{C}$ on a rotary tissue slicer and maintained for at least $2 \mathrm{hr}$ in the presence of a gas $\left(95 \% \mathrm{O}_{2}-5 \% \mathrm{CO}_{2}\right)$-saturated extracellular solution containing (in $\mathrm{mm}$ ): $124 \mathrm{NaCl}, 3 \mathrm{KCl}, 2 \mathrm{CaCl}_{2}, 2$ $\mathrm{MgSO}_{4}, 22.5 \mathrm{NaHCO}_{3}$, and 10 glucose (at $25-26^{\circ} \mathrm{C}$ ). Before each experiment, individual slices were transferred to a submersion-recording chamber, in which they were superfused continuously $(2 \mathrm{ml} / \mathrm{min})$ with extracellular solution at $28^{\circ} \mathrm{C}$.

Extracellular field potentials were recorded in the stratum radiatum by using glass electrodes $(5-15 \mathrm{M} \Omega$ resistance, filled with $0.5 \mathrm{M} \mathrm{NaCl}$ ). Whole-cell patch-clamp recordings were made from CA1 pyramidal cell bodies by using a blind patch-clamp technique. The patch electrodes (glass with filament, 5-8 $\mathrm{M} \Omega$ resistance; World Precision Instruments, Sarasota, FL) were filled with internal solution containing (in $\mathrm{mm}$ ): 130 cesium methanesulfonate, 10 tetraethylammonium chloride, $5 \mathrm{NaCl}, 0.25$ 
BAPTA, 2 ATP, 0.3 GTP, and 10 HEPES, pH 7.3 adjusted with $\mathrm{CsOH}$ (osmolarity, 290-300 mOsm). In some experiments, either $10 \mu \mathrm{M} \mathrm{F} \mathrm{K506,}$ a specific $\mathrm{CaN}$ inhibitor, or $500 \mu \mathrm{M}$ CaN-AIP (CaN auto-inhibitory peptide) was included in the internal solution to inhibit postsynaptic $\mathrm{CaN}$ activity. Whole-cell recordings were made of the CA1 pyramidal layer. The cell type was identified from the half-width of the action potential: the action potential of interneurons is short [usually $0.5 \mathrm{msec}$ (known as a fast spike)], in contrast to $1 \mathrm{msec}$ for pyramidal neurons. During the course of the experiment, the membrane potential of the postsynaptic cell was held at $-80 \mathrm{mV}$ (with an Axopatch-200B amplifier; Axon Instruments, Foster City, CA), except when an LTD-inducing stimulus was applied, when it was held under current-clamp configuration. Series and input resistances were monitored throughout each experiment. Cells were excluded from data analysis if more than a $20 \%$ change in series or input resistance occurred during the course of the experiment. Data were collected and analyzed (filtered at $2 \mathrm{kHz}$, sampled at $5 \mathrm{kHz}$ ) on a personal computer running the Axobasic program (Axon Instruments).

The Schaffer collateral-commissural fibers in the stratum radiatum of the CA1 region were stimulated every $20 \mathrm{sec}$ through a concentric bipolar electrode with 0.3 msec constant-current pulses at an intensity sufficient to evoke $50-60 \%$ of the maximum synaptic response. The amplitudes of the field EPSPs were calculated as the initial slope of the EPSP. The amplitudes of the EPSCs were measured by taking the average of a 2 msec window around the peak of the EPSC relative to the baseline. Low-frequency stimulation (LFS)-induced LTD was obtained by using a $1 \mathrm{~Hz}$ stimulus for $15 \mathrm{~min}$ in field potential recording or $10 \mathrm{~min}$ in whole-cell patch-clamp recording. LTD values were calculated as the ratio of the average of the stable response after induction (typically at 55-60 min for field potential recordings and at 35-40 min for whole-cell recordings after LFS) and that before the induction of LTD (at $0-20 \mathrm{~min}$ before LFS).

FK506 was a gift from Fujisawa Pharmaceutical (Osaka, Japan); rapamycin and CaN-AIP were obtained from Calbiochem-Novabiochem (La Jolla, CA); BAPTA was obtained from Sigma-Aldrich (St. Louis, MO); $(R S)$ - $\alpha$-methyl-4-carboxyphenylglycine (MCPG), [CRS]-1-aminoindan1,5-dicarboxylic acid (AIDA), 2-methyl-6-(phenylethynyl)pyridine (MPEP), [2s]- $\alpha$-ethylglutamic acid (EGLU), (RS)- $\alpha$-methylserine-ophosphate monophenyl ester (MSOPPE), ( \pm )-1-aminocyclopentanetrans-1,3-dicarboxylic acid (trans-ACPD), $(2 S, 3 S, 4 S)$-CCG/(2S,1S,2S)-2(carboxycyclopropyl) (L-CCG-1), and kynurenic acid were obtained from Tocris Cookson (Ballwin, MO). FK506 and rapamycin were dissolved in dimethylsulfoxide. AIDA, EGLU, MSOPPE, trans-ACPD, and L-CCG-1 were dissolved in $\mathrm{NaOH}(100 \mathrm{~mm})$. Other substances were dissolved in distilled water. These substances were diluted to final concentrations with standard extracellular solution.

\section{RESULTS}

\section{LTD induction in P6-P8 rat hippocampal neurons was} dependent on activation of mGluRs but not NMDARs

Typical field potential LTD was observed in slices from P6-P8 rats $(-29.7 \pm 5.3 \% ; n=5$; data not shown). This LTD was not blocked by bath application of the selective NMDAR antagonist D-AP-5 (50 $\mu \mathrm{M} ;-33.4 \pm 2.1 \% ; n=5)$ (Fig. $1 A)$. In the presence of the groups I/II mGluR antagonist MCPG $(500 \mu \mathrm{M})$, only a transient depression in synaptic transmission occurred and not LTD $(-2.1 \pm 2.3 \% ; n=7)$ (Fig. $1 B)$. These results confirm previous reports that the activity of mGluRs is required for LTD induction in P6-P8 rat CA1 neurons (Bolshakov and Siegelbaum, 1994). To further investigate which group of mGluRs is involved in this LTD, we next examined the effect of specific antagonists for groups I and II mGluRs on this LTD induction. Neither group I mGluR antagonists AIDA $(500 \mu \mathrm{M})$ nor MPEP $(10 \mu \mathrm{M})$ suppressed LTD induction [Fig. 1C: AIDA, filled circles $(-27.7 \pm$ $3.2 \% ; n=7)$; MPEP, open triangles $(-23.4 \pm 5.8 \% ; n=5)]$, although MPEP slightly inhibited the transient depression after LFS. Because MPEP is a more selective antagonist of mGluR5 than AIDA (Mannaioni et al., 2001), the difference in the transient depression could be explained by the different function of each receptor subtype in synaptic transmission. In contrast, both selective group II mGluR antagonists EGLU $(50 \mu \mathrm{M} ;-2.2 \pm$

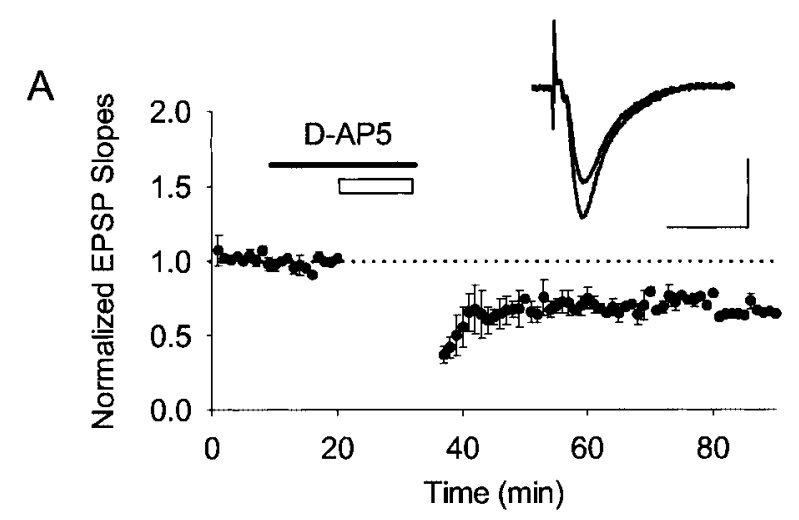

B
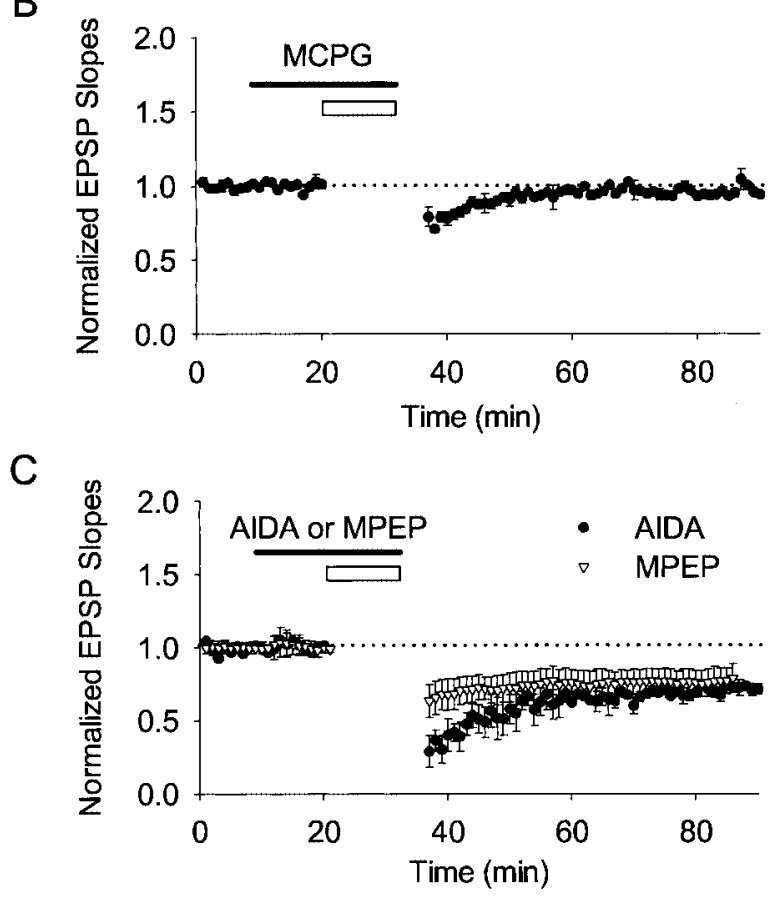

D

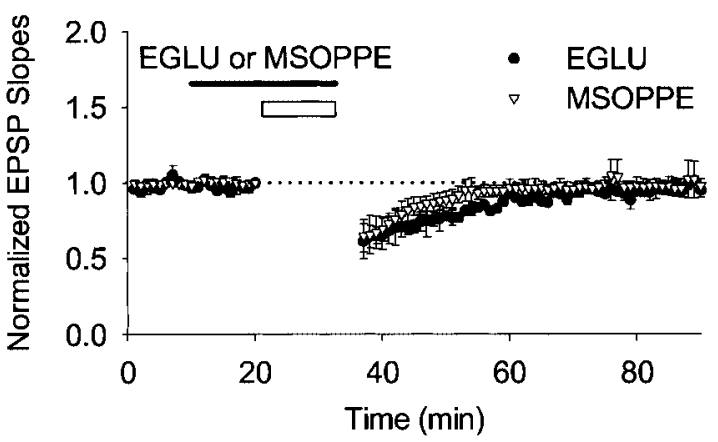

Figure 1. In P6-P8 rats, LTD induction is fully dependent on group II mGluR activity. The figure shows averaged field potential recordings. The initial slopes of field EPSPs were normalized to the baseline value preceding the induction of LTD. Each data point represents mean \pm SEM. Open bars indicate LFS of $1 \mathrm{~Hz}$ for $15 \mathrm{~min}$. $A$, LFS given in the presence of D-AP-5 evoked LTD $(n=5)$. Inset, Representative field EPSPs before and $50 \mathrm{~min}$ after LFS. Calibration: $20 \mathrm{msec}, 1 \mathrm{mV}$. $B-D$, This induction was blocked by bath application of MCPG $(n=7)$, EGLU $(n=6)$, and $\operatorname{MSOPPE}(n=6)$ but not by AIDA $(n=7)$ or MPEP $(n=5)$. 
A

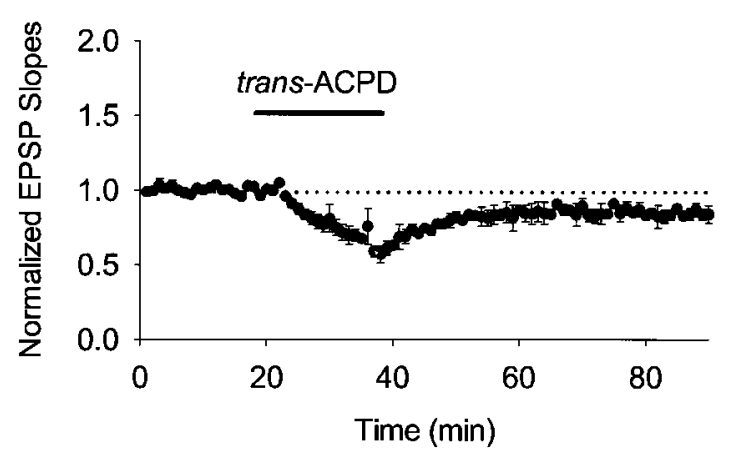

B

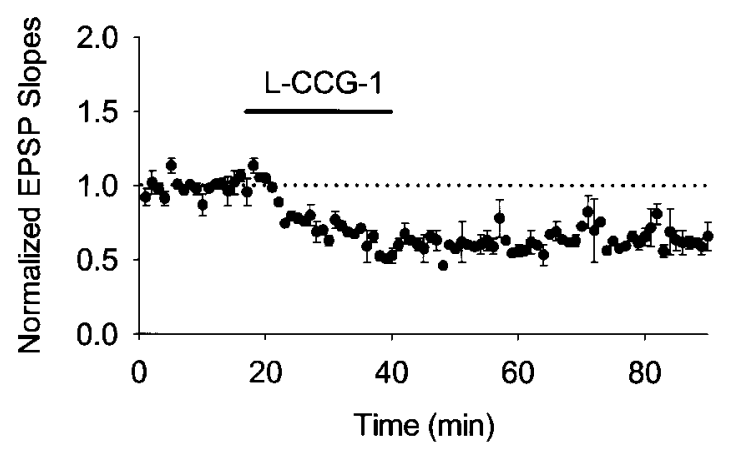

Figure 2. In P6-P8 rats, bath application of mGluR agonists evoked LTD. The figure shows averaged field potential recordings. The initial slopes of field EPSPs were normalized to the baseline value preceding the induction of LTD. Each data point represents mean \pm SEM. A, Bath application of trans-ACPD induced LTD $(n=6)$. B, Bath application of L-CCG-1 induced LTD $(n=6)$.

$1.6 \% ; n=6)($ Fig. $1 D$, filled circles $)$ and MSOPPE $(50 \mu \mathrm{M} ;-1.3 \pm$ $5.9 \% ; n=6$ ) (Fig. $1 D$, open triangles) completely blocked this LTD. These results demonstrate that induction of LTD in P6-P8 rat CA1 neurons requires activation of group II mGluRs.

Is activation of group II mGluRs alone sufficient to induce LTD? To address this issue, we applied mGluR agonists without giving LFS. Bath application of trans-ACPD (50 $\mu \mathrm{M})$, an agonist of groups I/II mGluRs, for 20 min evoked LTD $(-15.9 \pm 3.8 \%$; $n=6$ ) (Fig. $2 A$ ). Furthermore, bath application of L-CCG-1 (20 $\mu \mathrm{M}$ ), a specific group II mGluR agonist (Neugebauer et al., 2000a,b), also induced LTD (-37.6 $\pm 6.1 \% ; n=5)$ (Fig. 2B). These results strongly suggest that activation of group II mGluRs in CA1 neurons of P6-P8 rats is sufficient for inducing LTD.

\section{Group II mGluR-dependent LTD is inhibited by CaN in P21-P25 rats}

We then tested LTD induction in slices from P21-P25 rats. A robust LTD was induced by LFS $(-24.8 \pm 3.0 \%$; $n=6)$ (Fig. $3 A)$. In contrast to the observations from the P6-P8 rats (Fig. 1), D-AP-5 blocked LTD induction ( $50 \mu \mathrm{M} ; 1.5 \pm 1.2 \%$; $n=7$ ) (Fig. $3 B$, filled circles $)$, but MCPG did not $(500 \mu \mathrm{M} ;-22.3 \pm 3.2 \% ; n=$ 5 ) (Fig. 3B, open triangles). On the other hand, bath application of neither trans-ACPD $(50 \mu \mathrm{M} ; 3.8 \pm 6.1 \% ; n=6)$ (Fig. $3 C)$ nor L-CCG-1 (20 $\mu \mathrm{M} ; 8.1 \pm 6.5 \% ; n=6)$ (Fig. $3 D)$ induced LTD. These results demonstrate that LTD induction in P21-P25 rats requires activation of NMDARs but not group II mGluRs. The change from mGluR to NMDAR dependency in LTD induction during postnatal development implies that an age-dependent regulation is involved in LTD induction.
A

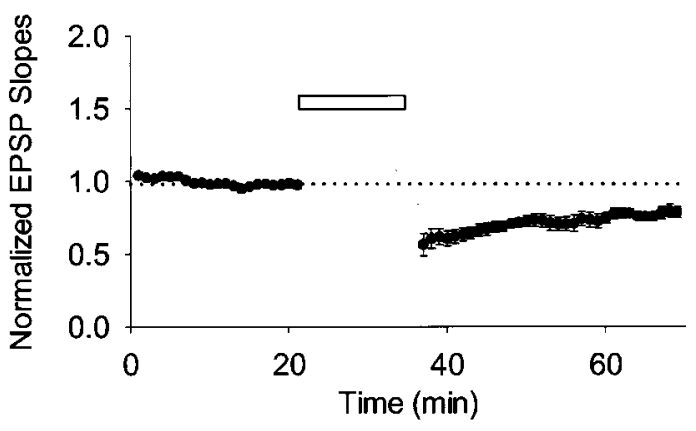

B

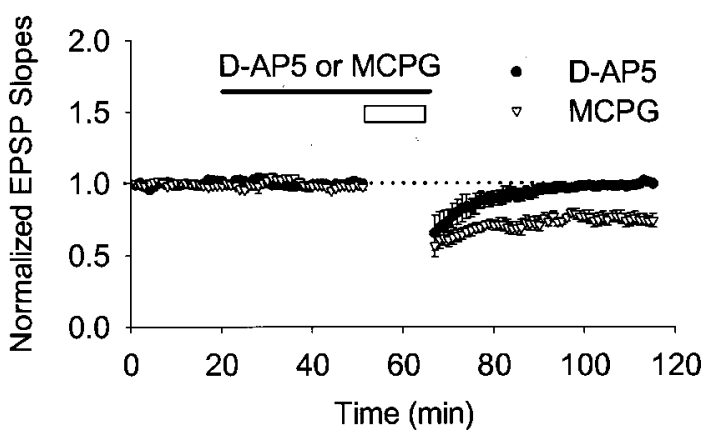

$\mathrm{C}$

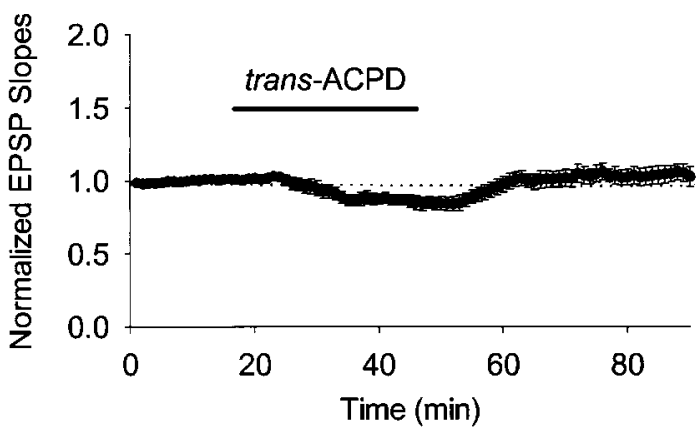

$\mathrm{D}$

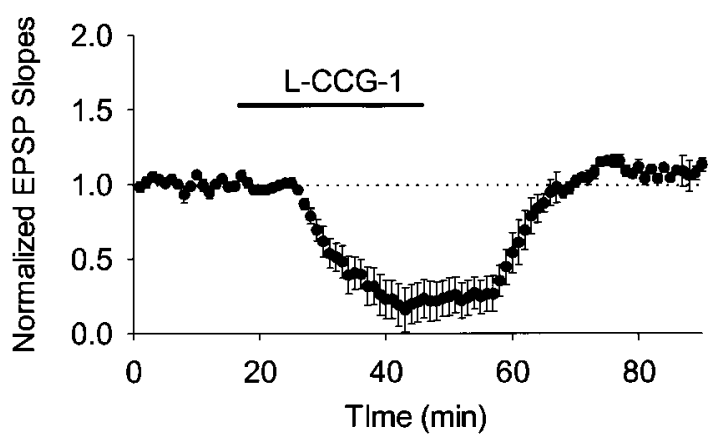

Figure 3. In P21-P25 rats, NMDAR-dependent, but not mGluRdependent, LTD was induced. The figure shows averaged field potential recordings. The initial slopes of field EPSPs were normalized to the baseline value preceding the induction of LTD. Each data point represents mean \pm SEM. Open bars indicate the LFS of $1 \mathrm{~Hz}$ for $15 \mathrm{~min}$. A, A typical LTD was induced by LFS $(n=6)$. $B$, Bath application of D-AP-5 ( filled circles), but not MCPG (open triangles), blocked LTD induction. $C$, Bath application of trans-ACPD failed to induce LTD. D, Bath application of L-CCG-1 failed to induce LTD.

Polli et al. (1991) demonstrated immunohistochemically that $\mathrm{CaN}$ is expressed in rat brain in an age-dependent manner; it is first detectable on postnatal day 4 and reaches a plateau after day 20. The consistency between the developmental increase in the expression of $\mathrm{CaN}$ and the age-dependent change in mechanisms 


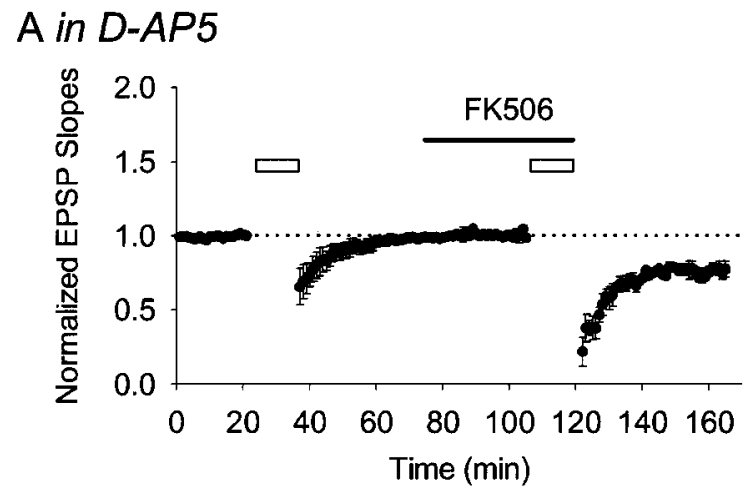

$\mathrm{C}$ in D-AP5 and FK506

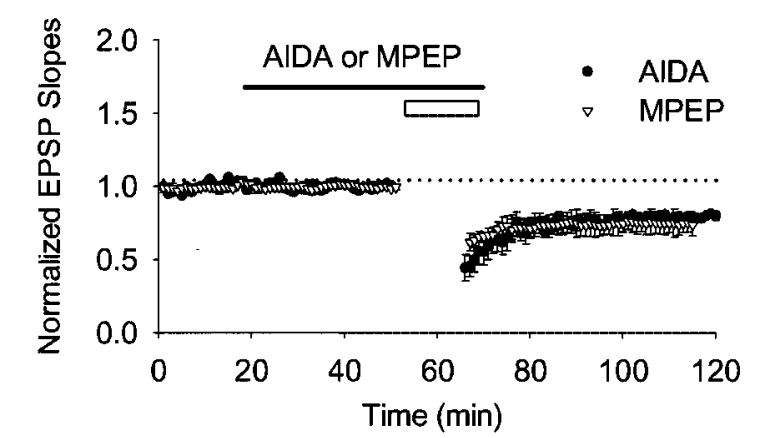

$\mathrm{E}$ in $D-A P 5$

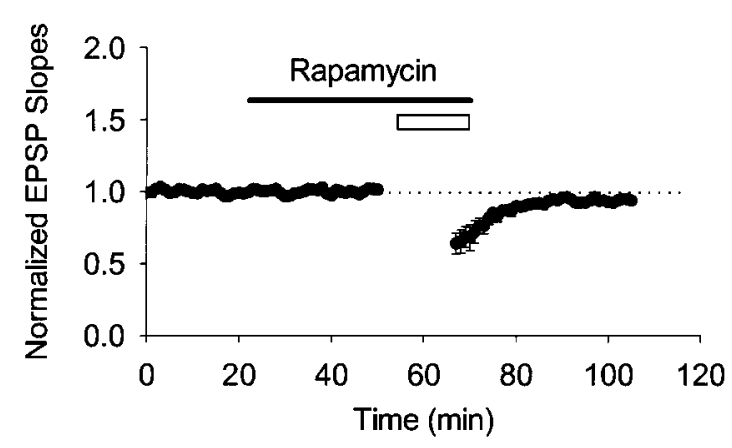

$B$ in D-AP5 and FK506

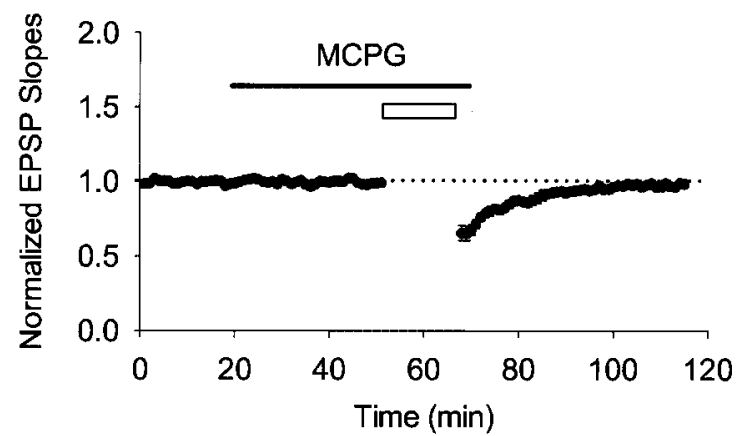

$D$ in D-AP5 and FK506

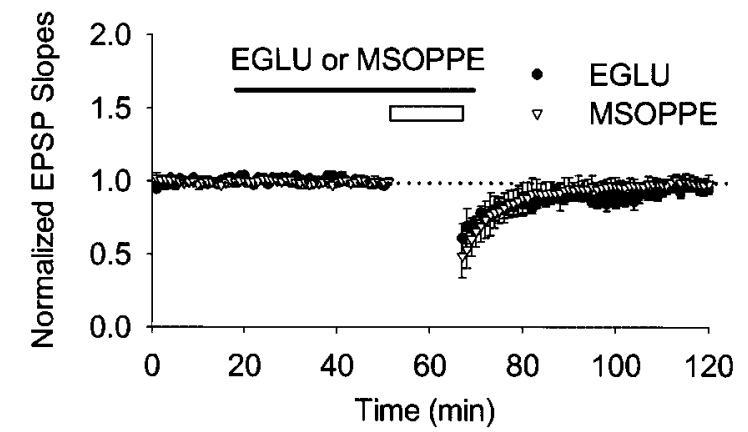

$\mathbf{F}$

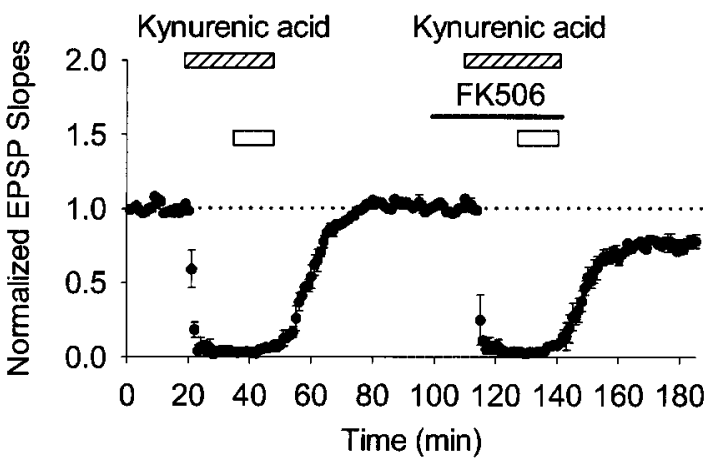

Figure 4. In P21-P25 rats, bath application of FK506 restored group II mGluR-dependent LTD. The figure shows field potential recordings. The initial slopes of field EPSPs were normalized to the baseline value preceding the induction of LTD. Each data point represents mean \pm SEM. Open bars indicate the LFS of $1 \mathrm{~Hz}$ for $15 \mathrm{~min}$. $A-E$, LFS applied in the presence of D-AP-5. A, LFS did not induce LTD. In the same slice, however, after application of FK506 for 30 min (black bar), the same stimulation elicited LTD $(n=7) . B-D$, This LTD was blocked by MCPG $(n=6)$, EGLU $(n=7)$, and MSOPPE $(n=7)$ but not by AIDA $(n=8)$ or MPEP $(n=7)$. E. LFS given after bath application of rapamycin $($ black bar $)$ for 30 min failed to induce LTD $(n=$ 5). F, Applying LFS together with kynurenic acid (hatched bar) failed to induce LTD. In the same slices, however, this induction protocol elicited LTD when given after bath application of FK506 (black bar) for $20 \mathrm{~min}(n=5)$.

underlying LTD raises the question of whether CaN activity is involved in this developmental process. It is well established that induction of NMDAR-dependent LTD in P21-P25 rats requires CaN activity (Mulkey et al., 1994; Hodgkiss and Kelly, 1995). To investigate whether $\mathrm{CaN}$ also contributes to mGluR-dependent LTD, we examined the induction of mGluR-dependent LTD in the presence of FK506, a specific CaN inhibitor. D-AP-5 was applied for $20 \mathrm{~min}$ before LFS and during LFS to block activities of NMDARs. Surprisingly, applying LFS in the presence of FK506 $(10 \mu \mathrm{M} ;-20.1 \pm 5.3 \% ; n=7)$ (Fig. $4 A)$, but not in its absence $(n=7)$ (Figs. 3B, $4 A$ ), induced a robust LTD. This LTD was blocked by MCPG $(500 \mu \mathrm{M} ;-2.5 \pm 2.2 \% ; n=6)($ Fig. $4 B)$, EGLU (50 $\mu \mathrm{M} ;-8.1 \pm 1.2 \% ; n=7)$ (Fig. 4D, filled circles), and MSOPPE $(50 \mu \mathrm{M},-2.1 \pm 2.9 \% ; n=7)$ (Fig. $4 D$, open triangles) but not by AIDA $(500 \mu \mathrm{M} ;-20.8 \pm 1.3 \% ; n=8)$ (Fig. $4 C$, filled circles) or MPEP $(10 \mu \mathrm{M} ;-24.9 \pm 3.1 \% ; n=7)$ (Fig. $4 C$, open triangles). Although LTD was evoked in the presence of FK506, applying LFS (still in the presence of D-AP-5) in the presence of rapamycin $(10 \mu \mathrm{M} ;-5.7 \pm 0.7 \% ; n=5)$ (Fig. $4 E)$, an FK506 analog that does not inhibit CaN activity, failed to elicit LTD. Together, these observations demonstrate that $\mathrm{CaN}$ inhibits group II mGluR-dependent LTD in P21-P25 rats.

$\mathrm{CaN}$ inhibitors prolong NMDAR channel openings or prevent NMDAR desensitization (Lieberman and Mody, 1994; Tong et al., 1995). It is possible that NMDAR channel activity was enhanced in the presence of FK506, and thus D-AP-5 could not block the channel activity. To examine this issue, we took advantage of the nonspecific ionotropic glutamate receptor antagonist kynurenic acid, which inhibits both NMDAR and AMPA receptor activities, to test LTD induction in the presence and absence 
A

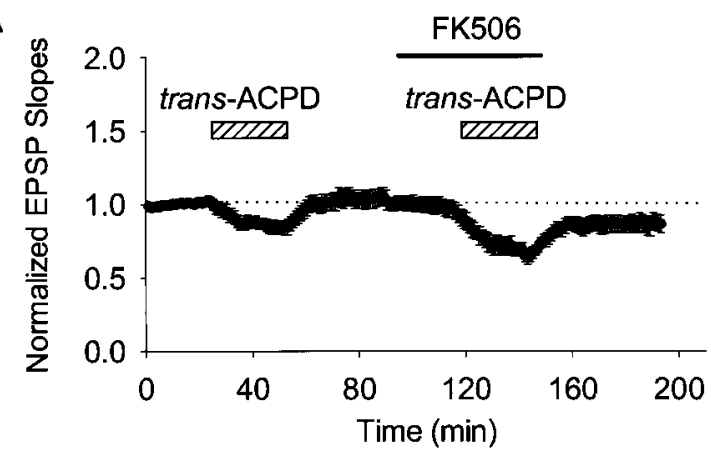

B

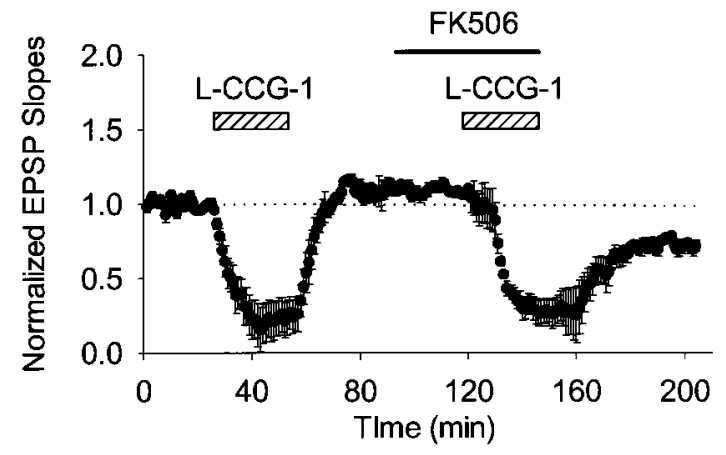

Figure 5. In P21-P25 rats, bath application of FK506 restored agonistsinduced group II mGluR-dependent LTD. The figure shows averaged field potential recordings. The initial slopes of field EPSPs were normalized to the baseline value preceding the induction of LTD. Each data point represents mean \pm SEM. A, Bath application of trans-ACPD (hatched bars) resulted in transient depression of field EPSPs but not in LTD. In the same slices, however, the same concentration of trans-ACPD in the presence of FK506 (black bar) resulted in LTD $(n=6)$. B, Bath application of L-CCG-1 (hatched bars) resulted in transient depression of field EPSPs but not in LTD. In the same slices, however, the same concentration of L-CCG-1 in the presence of FK506 (black bar) induced $\operatorname{LTD}(n=6)$.

of FK506. Bath application of kynurenic acid (10 mM) for $10 \mathrm{~min}$ before LFS eliminated field EPSPs and blocked induction of LTD $(-3.0 \pm 2.5 \% ; n=5)$ (Fig. $4 F)$. After bath application of FK506 for $20 \mathrm{~min}$, however, the same stimulation induced LTD in the same slices $(-22.5 \pm 3.8 \% ; n=5)($ Fig. $4 F)$. These results further confirm that LTD induction in the presence of FK506 is mGluR dependent but not NMDAR dependent.

On the other hand, bath application of both trans-ACPD (50 $\mu \mathrm{M} ;-13.6 \pm 2.0 \% ; n=6)$ (Fig. $5 A$ ) and L-CCG-1 (20 $\mu \mathrm{M}$; $-27.6 \pm 4.3 \% ; n=6$ ) (Fig. $5 B$ ) evoked LTD in the presence of FK506 $(10 \mu \mathrm{M})$, although applying them alone failed to induce any LTD (Figs. 3C,D, $5 A, B$ ). Thus, bath application of FK506 restored both LFS- and agonist-induced group II mGluRdependent LTD in P21-P25 rats.

We showed that antagonists of group I mGluRs did not affect LTD induction in P21-P25 rats (Fig. 4C). Previous studies, however, have reported that group I mGluR antagonists blocked LTD in area CA1 (Oliet et al., 1997; Nicoll et al., 1998; Huber et al., 2001; Kleppisch et al., 2001). One likely explanation for this difference is the input strength dependency of the group I mGluR-dependent LTD. Oliet et al. (1997) observed that group I mGluR-dependent LTD could be elicited with low-strength input stimuli (output, $0.05-0.1 \mathrm{mV} / \mathrm{msec}$ ) but not with greater input stimuli $(0.15-0.2 \mathrm{mV} / \mathrm{msec})$. In our experiment, the Schaffer collateral-commissural fibers were stimulated at an intensity sufficient to evoke $50-60 \%$ of the maximum synaptic response; the outputs were $0.15-0.4 \mathrm{mV} / \mathrm{msec}$. To confirm whether the induction of group I mGluR-dependent LTD requires a different strength of input stimuli from that of group II mGluR-dependent LTD, we tested LTD induction with both weak and strong stimulation in P21-P25 rats. In all four examined slices, strong stimulation (output, $0.15-0.4 \mathrm{mV} / \mathrm{msec}$ ) paired with LFS did not induce any LTD in the presence of $100 \mu \mathrm{M}$ D-AP-5 (2.3 $\pm 7.2 \%$; data not shown). When we reduced the input strength to induce an output of $0.05-0.1 \mathrm{mV} / \mathrm{msec}$, however, LFS did induce a persistent LTD in these same slices $(-35.6 \pm 9.7 \%$; data not shown). On the other hand, in the presence of AIDA $(500 \mu \mathrm{M}$; still in the presence of D-AP-5), LFS failed to induce any LTD even when paired with weak stimulation in all three examined slices $(10.1 \pm 5.9 \%$; data not shown $)$. These results are consistent with the previous observation that induction of group I mGluRdependent LTD requires low-strength input stimuli (Oliet et al., 1997) and show that the induction of group II mGluR-dependent LTD requires high-strength input in the absence of CaN activity.

\section{Presynaptic CaN contributes to inhibition of group II mGluR-dependent LTD, and postsynaptic CaN activity is required for NMDAR-dependent LTD}

Next we examined the role of $\mathrm{CaN}$ in the induction of NMDARdependent LTD in P21-P25 rats. LFS given in the presence of MCPG induced LTD $(-22.3 \pm 3.2 \% ; n=5$; data not shown), which was completely blocked by bath application of FK506 (10 $\mu \mathrm{M} ;-2.5 \pm 2.2 \% ; n=6$; data not shown) but not rapamycin (10 $\mu \mathrm{M} ;-26.3 \pm 3.8 \% ; n=4$; data not shown). These results confirm that $\mathrm{CaN}$ activity is required for induction of NMDARdependent LTD (Mulkey et al., 1994; Hodgkiss and Kelly, 1995).

According to previous reports (Mulkey et al., 1994), postsynaptic, but not presynaptic, $\mathrm{CaN}$ activity is involved in NMDARdependent LTD. Therefore, it is necessary to verify whether the $\mathrm{CaN}$ that contributed to the inhibition of group II mGluRdependent LTD was presynaptic or postsynaptic. To answer this question, we examined LTD induction by using whole-cell patchclamp recording in individual CA1 neurons of P21-P25 rats. The mGluR-dependent LTD and NMDAR-dependent LTD were examined in the presence of D-AP-5 and MCPG, respectively. Applying LFS ( $1 \mathrm{~Hz}$ for $10 \mathrm{~min})$ evoked LTD (-22.9 $\pm 4.8 \%$; $n=6$ ) (Fig. $6 A$, open triangles). This LTD was blocked by D-AP-5 $(50 \mu \mathrm{M} ;-1.2 \pm 3.9 \% ; n=5)$ (Fig. 6 A, filled circles). We next incubated the slices in a solution containing FK506 $(10 \mu \mathrm{M})$ for 20-30 min before the patch-clamp recording. Consistent with observations from field potential recording (Fig. 4), in these FK506-incubated slices, LFS evoked LTD even in the presence of D-AP-5 $(-23.3 \pm 4.3 \% ; n=5)$ (Fig. $6 B$, filled circles) but not in the presence of D-AP-5 paired with EGLU $(-1.2 \pm 3.5 \%$; $n=$ 6) (Fig. 6B, open triangles). These results further confirm that CaN inhibits group II mGluR-dependent LTD in individual CA1 pyramidal neurons. To block postsynaptic $\mathrm{CaN}$ activity in particular, we next applied FK506 $(10 \mu \mathrm{M})$ through the patch pipette. In contrast to bath application of FK506, applying LFS failed to induce the group II mGluR-dependent LTD during postsynaptic application of FK506 (-2.6 $\pm 2.2 \% ; n=5)$ (Fig. 6C, open triangles). Because FK506 can permeate cell membranes, it is possible that it diffuses out from postsynaptic neurons to other regions, including presynaptic regions. So we used CaN-AIP, which cannot permeate cell membranes, to examine this possibility. LFS applied during postsynaptic diff usion of CaN-AIP (500 


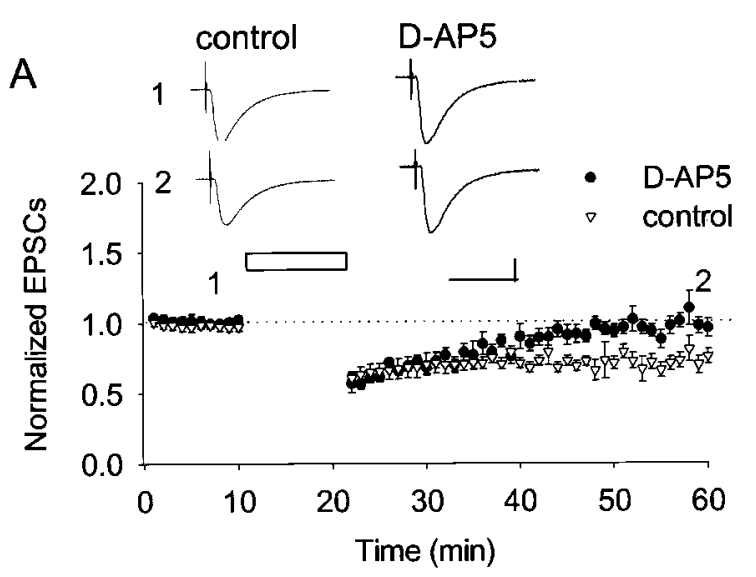

$B$ in D-AP5 and FK506

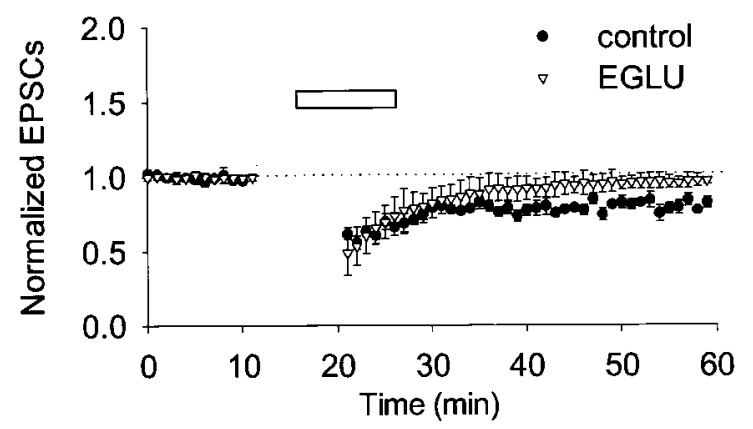

C in D-AP5

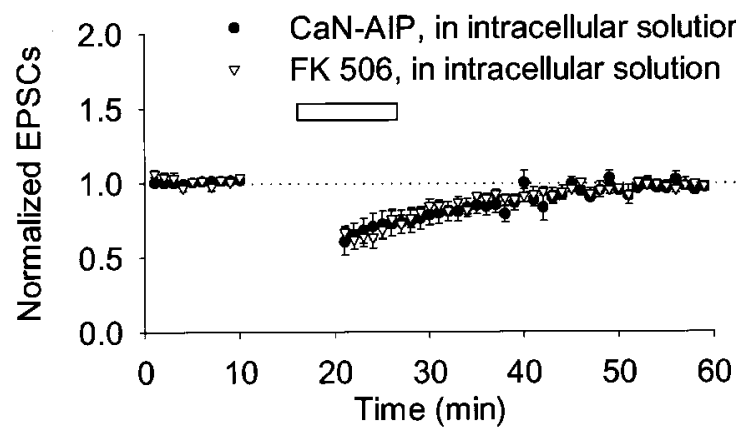

$D$ in $M C P G$

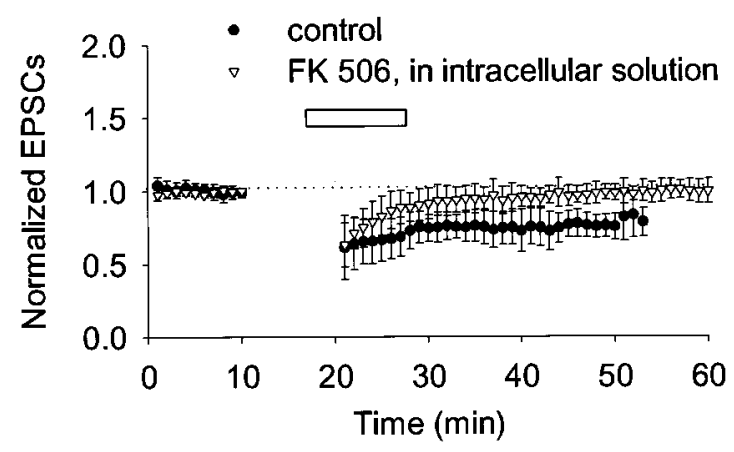

Figure 6. Presynaptic CaN contributes to inhibition of group II mGluRdependent LTD, and postsynaptic CaN activity is required for NMDARdependent LTD. The figure shows averaged whole-cell EPSC recordings in slices from P21-P25 rats. The initial slopes of field EPSPs were normalized to the baseline value preceding the induction of LTD. Each data point represents mean \pm SEM. Open bars indicate LFS of $1 \mathrm{~Hz}$ for 10 min. $A$, Applying LFS led to LTD in control slices $(n=6)$. This LTD was blocked by bath application of D-AP-5 $(n=5)$. Insets, Sample waveforms taken at the times indicated, from a typical experiment. $\mu \mathrm{M})$ also failed to induce group II mGluR-dependent LTD $(-2.0 \pm 3.2 \% ; n=5)$ (Fig. $6 C$, filled circles).

On the other hand, applying LFS in the presence of MCPG (1 $\mathrm{mM})$ induced NMDAR-dependent LTD $(-21.7 \pm 5.4 \% ; n=6)$ (Fig. 6D, filled circles). In agreement with the report of Mulkey et al. (1994), postsynaptic application of FK506 $(0.5 \pm 3.8 \%, n=6)$ (Fig. 6D, open triangles) inhibited this LTD. Together, these results demonstrate that postsynaptic $\mathrm{CaN}$ activity is required for induction of NMDAR-dependent LTD, whereas presynaptic CaN contributes to inhibition of group II mGluR-dependent LTD.

\section{DISCUSSION}

mGluR-dependent LTD in hippocampal CA1 neurons has been reported by many groups (Bashir et al., 1993; Bear and Malenka, 1994; Otani and Connor, 1995; Zhuo and Hawkins, 1995; Overstreet et al., 1997; Fitzjohn et al., 1998; Otani and Connor, 1998; Reyes-Harde and Stanton, 1998; Bortolotto et al., 1999; Kemp and Bashir, 1999; Bolshakov et al., 2000; Li et al., 2000). Although an in vivo study (Manahan-Vaughan, 1997) has demonstrated the involvement of group II rather than group I mGluR activity in LTD induction, most in vitro studies have examined group I mGluR-dependent LTD (Nicoll et al., 1998; Huber et al., 2001; Kleppisch et al., 2001). On the other hand, group II mGluRdependent LTD has been demonstrated in the medial perforant path of the dentate gyrus (Huang et al., 1997, 1999; Kulla et al., 1999) and in mossy fiber-CA3 synapses (Yokoi et al., 1996; Manabe, 1997). Our study is the first to investigate the mechanisms underlying group II mGluR-dependent LTD in the CA1 pyramidal neurons in vitro.

The induction of mGluR-dependent LTD that has been reported is age dependent: it could be evoked in immature rats (3-12 d) but not in rats older than $28 \mathrm{~d}$ (Bolshakov and Siegelbaum, 1994; Overstreet et al., 1997). Consistent with these reports, we found that in P6-P8 rats, applying both LFS and agonists of group II mGluRs induced LTD. In contrast, in P21P25 rats, neither treatment evoked LTD. These data prove that the induction of group II mGluR-dependent LTD is age dependent. The specific CaN inhibitor FK506, but not rapamycin, restored both LFS-induced (Fig. 4) and agonist-induced (Fig. 5) group II mGluR-dependent LTD in P21-P25 rats. Taking these results together with the age-dependent expression of $\mathrm{CaN}$ (Polli et al., 1991), we conclude that group II mGluR-dependent LTD is age-dependently regulated by $\mathrm{CaN}$ (Fig. 7); CaN does not inhibit group II mGluR-dependent LTD in P6-P8 rats, because it is only weakly expressed in very young rats but is expressed strongly enough to inhibit group II mGluR-dependent LTD in P21-P25 rats.

Bath application of FK506 (Figs. $4 A, F, 6 B$ ), but not postsynaptic injection of either FK506 or CaN-AIP (Fig. $6 C$ ), restored the group II mGluR-dependent LTD, confirming that the site of action of $\mathrm{CaN}$ in this case is not postsynaptic. Along with the presynaptic expression of group II mGluRs in CA1 region (Pin and Duvoisin, 1995; Petralia et al., 1996; Wright and Schoepp,

$\leftarrow$

$B$, FS given in the presence of D-AP-5 paired with FK506 in extracellular solution induced LTD $(n=5)$. This LTD was blocked by EGLU $(n=6)$. $C$, During postsynaptic diffusion of FK506 (open triangles; $n=5$ ) or CaN-AIP ( filled circles; $n=5$ ) through the patch pipette, LFS given in the presence of D-AP-5 failed to induce LTD. $D$, In the presence of MCPG, applying LFS evoked LTD $(n=6)$. Postsynaptic diff usion of FK506 blocked this LTD $(n=6)$. 


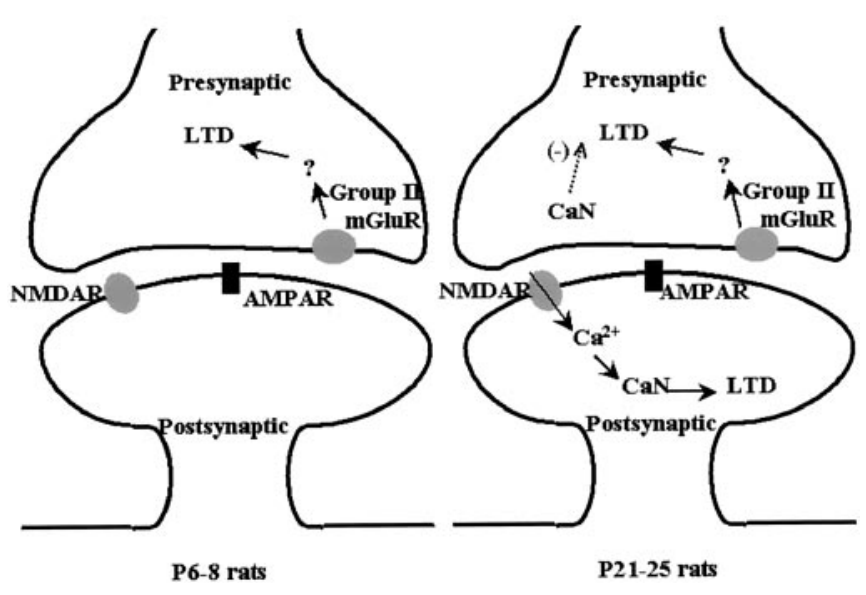

Figure 7. Schematic diagram showing that $\mathrm{CaN}$ developmentally regulates group II mGluR- and NMDAR-dependent LTD. In P6-P8 rats, $\mathrm{CaN}$ does not inhibit induction of group II mGluR-dependent LTD, because it is only weakly expressed in very young rats. In P21-P25 rats, however, $\mathrm{CaN}$ was expressed strongly enough to inhibit this LTD via a presynaptic mechanism. On the other hand, postsynaptic $\mathrm{CaN}$ facilitates the induction of NMDAR-dependent LTD.

1996; Anwyl, 1999), these findings strongly suggest that presynaptic, but not postsynaptic, $\mathrm{CaN}$ inhibits this LTD induction. $\mathrm{CaN}$ has been considered a key molecule in the induction of NMDAR-dependent LTD (Mulkey et al., 1994; Hodgkiss and Kelly, 1995). Using field potential recording (data not shown) and whole-cell recording (Fig. $6 D$ ), we also observed that both bath application and postsynaptic injection of FK506 blocked LTD induction in the presence of MCPG, thereby confirming the requirement of postsynaptic $\mathrm{CaN}$ activity in the induction of NMDAR-dependent LTD. Taking these results together, we conclude that $\mathrm{CaN}$ has opposite roles in the two forms of LTD, depending on its location: postsynaptic $\mathrm{CaN}$ promotes induction of NMDAR-dependent LTD, whereas presynaptic CaN inhibits group II mGluR-dependent LTD. The developmental and subcellular location-dependent regulation of LTD induction by $\mathrm{CaN}$ is schematized in Figure 7. These findings provide new insight into the functional aspects of $\mathrm{CaN}$ signaling in the regulation of synaptic plasticity and may help further elucidate the mechanisms underlying group II mGluR-dependent LTD.

Input strength influences the ability to generate different groups of mGluR-dependent LTD: induction of group I mGluRdependent LTD requires low-strength input stimuli, whereas induction of group II mGluR-dependent LTD requires greater input stimuli. These results might be assigned to the interaction between mGluR and the GABA receptor or to glutamate spillover. These data may help further elucidate the mechanisms underlying group I and II mGluR-dependent LTD.

What is the target molecule of $\mathrm{CaN}$ in group II mGluRdependent LTD? Reyes and Stanton (1996) reported that the induction of hippocampal LTD requires $\mathrm{Ca}^{2+}$ release from presynaptic ryanodine-sensitive $\mathrm{Ca}^{2+}$ stores. $\mathrm{CaN}$ modulates intracellular $\mathrm{Ca}^{2+}$ mobility and cell excitability by acting on a variety of ion channels, including the ryanodine receptor (Chen et al., 1995; Marrion, 1996; Zhu and Yakel, 1997; Lukyanetz et al., 1998; Bandyopadhyay et al., 2000; Burley and Sihra, 2000). These channels or adenylyl cyclase (Antoni et al., 1998), which is activated by group II mGluRs, are likely the target molecules of $\mathrm{CaN}$ involving LTD induction. The physiological role of group II
mGluR-dependent LTD in the hippocampus is not yet known. If we take into account the age dependency of group II mGluRdependent LTD (that is, the LTD is suppressed in a maturing brain), group II mGluR-dependent LTD might be involved in developmental processes, such as axonal growth (Koyama et al., 2002) and pruning (Overstreet et al., 1997). Inhibition of GABA receptor activity, which could be mediated by group II mGluRs (Doi et al., 2002), led to decreased synaptic density (Ferreira, 1999), which suggests the contribution of group II mGluRs to synaptogenesis. Additional investigation is needed to elucidate the precise mechanism and physiological significance of group II mGluR-dependent LTD.

\section{REFERENCES}

Antoni FA, Palkovits M, Simpson J, Smith SM, Leitch AL, Rosie R, Fink G, Paterson JM (1998) $\mathrm{Ca}^{2+} /$ calcineurin-inhibited adenylyl cyclase, highly abundant in forebrain regions, is important for learning and memory. J Neurosci 18:9650-9661.

Anwyl R (1999) Metabotropic glutamate receptors: electrophysiological properties and role in plasticity. Brain Res Brain Res Rev 29:83-120.

Bandyopadhyay A, Shin DW, Ahn JO, Kim DH (2000) Calcineurin regulates ryanodine receptor/ $\mathrm{Ca}^{2+}$-release channels in rat heart. Biochem J 352:61-70.

Bashir ZI, Jane DE, Sunter DC, Watkins JC, Collingridge GL (1993) Metabotropic glutamate receptors contribute to the induction of longterm depression in the CA1 region of the hippocampus. Eur J Pharmacol 239:265-266.

Bear MF, Malenka RC (1994) Synaptic plasticity: LTP and LTD. Curr Opin Neurobiol 4:389-399.

Bliss TV, Collingridge GL (1993) A synaptic model of memory: longterm potentiation in the hippocampus. Nature 361:31-39.

Bolshakov VY, Siegelbaum SA (1994) Postsynaptic induction and presynaptic expression of hippocampal long-term depression. Science 264:1148-1152.

Bolshakov VY, Carboni L, Cobb MH, Siegelbaum SA, Belardetti F (2000) Dual MAP kinase pathways mediate opposing forms of longterm plasticity at CA3-CA1 synapses. Nat Neurosci 3:1107-1112.

Bortolotto ZA, Fitzjohn SM, Collingridge GL (1999) Roles of metabotropic glutamate receptors in LTP, LTD in the hippocampus. Curr Opin Neurobiol 9:299-304.

Burley JR, Sihra TS (2000) A modulatory role for protein phosphatase $2 \mathrm{~B}$ (calcineurin) in the regulation of $\mathrm{Ca}^{2+}$ entry. Eur $\mathrm{J}$ Neurosci 12:2881-2891.

Chen TC, Law B, Kondratyuk T, Rossie S (1995) Identification of soluble protein phosphatases that dephosphorylate voltage-sensitive sodium channels in rat brain. J Biol Chem 270:7750-7756.

Doi A, Ishibashi H, Jinno S, Kosaka T, Akaike N (2002) Presynaptic inhibition of GABAergic miniature currents by metabotropic glutamate receptor in the rat CNS. Neuroscience 109:299-311.

Ferreira A (1999) Abnormal synapse formation in agrin-depleted hippocampal neurons. J Cell Sci 112:4729-4738.

Fitzjohn SM, Bortolotto ZA, Palmer MJ, Doherty AJ, Ornstein PL, Schoepp DD, Kingston AE, Lodge D, Collingridge GL (1998) The potent mGlu receptor antagonist LY341495 identifies roles for both cloned and novel mGlu receptors in hippocampal synaptic plasticity. Neuropharmacology 37:1445-1458.

Hodgkiss JP, Kelly JS (1995) Only “de novo" long-term depression (LTD) in the rat hippocampus in vitro is blocked by the same low concentration of F K506 that blocks LTD in the visual cortex. Brain Res 705:241-246.

Huang LQ, Rowan MJ, Anwyl R (1997) mGluR II agonist inhibition of LTP induction, and mGluR II antagonist inhibition of LTD induction, in the dentate gyrus in vitro. NeuroReport 8:687-693.

Huang L, Killbride J, Rowan MJ, Anwyl R (1999) Activation of mGluRII induces LTD via activation of protein kinase A, protein kinase $\mathrm{C}$ in the dentate gyrus of the hippocampus in vitro. Neuropharmacology 38:73-83.

Huber KM, Roder JC, Bear MF (2001) Chemical induction of mGluR5and protein synthesis-dependent long-term depression in hippocampal area CA1. J Neurophysiol 86:321-325.

Kato K, Uruno K, Saito K, Kato H (1991) Both arachidonic acid and 1-oleoyl-2-acetyl glycerol in low magnesium solution induce long-term potentiation in hippocampal CA1 neurons in vitro. Brain Res 563:94-100.

Kemp N, Bashir ZI (1999) Induction of LTD in the adult hippocampus by the synaptic activation of AMPA/kainate and metabotropic glutamate receptors. Neuropharmacology 38:495-504.

Kleppisch T, Voigt V, Allmann R, Offermanns S (2001) G $\alpha_{\mathrm{q}}$-deficient mice lack metabotropic glutamate receptor-dependent long-term de- 
pression but show normal long-term potentiation in the hippocampal CA1 region. J Neurosci 21:4943-4948.

Koyama R, Yamada MK, Nishiyama N, Matsuki N, Ikegaya Y (2002) Group II metabotropic glutamate receptor activation is required for normal hippocampal mossy fibre development in the rat. J Physiol (Lond) 539:157-162.

Kulla A, Reymann KG, Manahan-Vaughan D (1999) Time-dependent induction of depotentiation in the dentate gyrus of freely moving rats: involvement of group 2 metabotropic glutamate receptors. Eur J Neurosci 11:3864-3872.

Li ST, Kato K, Mikoshiba K (2000) High $\mathrm{Ca}^{2+} / \mathrm{low} \mathrm{Mg}^{2+}$ solution induces long-term depression in rat CA1 pyramidal neurons. Neurosci Lett 283:141-144.

Lieberman DN, Mody I (1994) Regulation of NMDA channel function by endogenous $\mathrm{Ca}^{2+}$-dependent phosphatase. Nature 369:235-239.

Lisman J (1994) The CaM kinase II hypothesis for the storage of synaptic memory. Trends Neurosci 17:406-412.

Lukyanetz EA, Piper TP, Sihra TS (1998) Calcineurin involvement in the regulation of high-threshold $\mathrm{Ca}^{2+}$ channels in NG108-15 (rodent neuroblastoma $\times$ glioma hybrid) cells. J Physiol (Lond) 510:371-385.

Malenka RC, Nicoll RA (1993) NMDA-receptor-dependent synaptic plasticity: multiple forms and mechanisms. Trends Neurosci 16:521-527.

Manabe T (1997) Two forms of hippocampal long-term depression, the counterpart of long-term potentiation. Rev Neurosci 8:179-193.

Manahan-Vaughan D (1997) Group 1 and 2 metabotropic glutamate receptors play differential roles in hippocampal long-term depression and long-term potentiation in freely moving rats. $J$ Neurosci 17:3303-3311.

Mannaioni G, Marino MJ, Valenti O, Traynelis SF, Conn PJ (2001) Metabotropic glutamate receptors 1 and 5 differentially regulate CA1 pyramidal cell function. J Neurosci 21:5925-5934.

Marrion NV (1996) Calcineurin regulates M channel modal gating in sympathetic neurons. Neuron 16:163-173.

Mulkey RM, Endo S, Shenolikar S, Malenka RC (1994) Involvement of a calcineurin/inhibitor-1 phosphatase cascade in hippocampal longterm depression. Nature 369:486-488.

Neugebauer V, Zinebi F, Russell R, Gallagher JP, Shinnick-Gallagher P (2000a) Cocaine and kindling alter the sensitivity of group II, III metabotropic glutamate receptors in the central amygdala. J Neurophysiol 84:759-770.

Neugebauer V, Chen PS, Willis WD (2000b) Groups II, III metabotropic glutamate receptors differentially modulate brief and prolonged nociception in primate STT cells. J Neurophysiol 84:2998-3009.

Nicoll RA, Oliet SH, Malenka RC (1998) NMDA receptor-dependent and metabotropic glutamate receptor-dependent forms of long-term depression coexist in CA1 hippocampal pyramidal cells. Neurobiol Learn Mem 70:62-72

Oliet SH, Malenka RC, Nicoll RA (1997) Two distinct forms of longterm depression coexist in CA1 hippocampal pyramidal cells. Neuron 18:969-982.

Otani S, Connor JA (1995) Long-term depression of naive synapses in adult hippocampus induced by asynchronous synaptic activity. J Neurophysiol 73:2596-2601.

Otani S, Connor JA (1998) Requirement of rapid $\mathrm{Ca}^{2+}$ entry and synaptic activation of metabotropic glutamate receptors for the induction of long-term depression in adult rat hippocampus. J Physiol (Lond) 511:761-770.

Overstreet LS, Pasternak JF, Colley PA, Slater NT, Trommer BL (1997) Metabotropic glutamate receptor mediated long-term depression in developing hippocampus. Neuropharmacology 36:831-844.

Petralia RS, Wang YX, Niedzielski AS, Wenthold RJ (1996) The metabotropic glutamate receptors, mGluR2 and mGluR3, show unique postsynaptic, presynaptic and glial localizations. Neuroscience 71:949-976.

Pin JP, Duvoisin R (1995) The metabotropic glutamate receptors: structure and functions. Neuropharmacology 34:1-26.

Polli JW, Billingsley ML, Kincaid RL (1991) Expression of the calmodulin-dependent protein phosphatase, calcineurin, in rat brain: developmental patterns and the role of nigrostriatal innervation. Brain Res Dev Brain Res 63:105-119.

Reyes M, Stanton PK (1996) Induction of hippocampal long-term depression requires release of $\mathrm{Ca}^{2+}$ from separate presynaptic and postsynaptic intracellular stores. J Neurosci 16:5951-5960.

Reyes-Harde M, Stanton PK (1998) Postsynaptic phospholipase C activity is required for the induction of homosynaptic long-term depression in rat hippocampus. Neurosci Lett 252:155-158.

Stanton PK, Chattarji S, Sejnowski TJ (1991) 2-Amino-3phosphonopropionic acid, an inhibitor of glutamate-stimulated phosphoinositide turnover, blocks induction of homosynaptic long-term depression, but not potentiation, in rat hippocampus. Neurosci Lett 127:61-66.

Thiels E, Xie X, Yeckel MF, Barrionuevo G, Berger TW (1996) NMDA receptor-dependent LTD in different subfields of hippocampus in vivo and in vitro. Hippocampus 6:43-51.

Tong G, Shepherd D, Jahr CE (1995) Synaptic desensitization of NMDA receptors by calcineurin. Science 267:1510-1512.

Wright RA, Schoepp DD (1996) Differentiation of group 2 and group 3 metabotropic glutamate receptor cAMP responses in the rat hippocampus. Eur J Pharmacol 297:275-282.

Yang XD, Connor JA, Faber DS (1994) Weak excitation and simultaneous inhibition induce long-term depression in hippocampal CA1 neurons. J Neurophysiol 71:1586-1590.

Yokoi M, Kobayashi K, Manabe T, Takahashi T, Sakaguchi I, Katsuura G, Shigemoto R, Ohishi H, Nomura S, Nakamura K, Nakao K, Katsuki M, Nakanishi S (1996) Impairment of hippocampal mossy fiber LTD in mice lacking mGluR2. Science 273:645-647.

Zhu Y, Yakel JL (1997) Calcineurin modulates G protein-mediated inhibition of N-type calcium channels in rat sympathetic neurons. J Neurophysiol 78:1161-1165.

Zhuo M, Hawkins RD (1995) Long-term depression: a learning-related type of synaptic plasticity in the mammalian central nervous system. Rev Neurosci 6:259-277. 